\title{
Cranial base approaches to posterior circulation aneurysms
}

\section{J. Diaz Day, M.D., Takanori Fukushima, M.D., D.M.Sc., and Steven L. Giannotta, M.D.}

Lahey Hitchcock Medical Center, Burlington, Massachusetts; Allegheny Neuroscience Institute, Allegheny University of the Health Sciences, Allegheny General Hospital, Pittsburgh, Pennsylvania; and Department of Neurological Surgery, University of Southern California, Los Angeles, California

Aneurysms arising from the posterior circulation, especially when they are large and complex, continue to present a technical challenge. The development of cranial base strategies and principles has added to surgical management options. The authors used one of four cranial base approaches for the treatment of 30 patients with large and/or complex aneurysms arising from the vertebrobasilar circulation. These approaches included the extradural temporopolar, combined petrosal, retrolabyrinthine-transsigmoid, and the extreme-lateral inferior transtubercular exposure. The indications, technique, and results of each approach in this series are discussed, and a management paradigm is suggested for such aneurysms.

\section{Key Words * aneurysm * posterior fossa * surgical approach * cranial base surgery * basilar} artery

Aneurysms residing in the posterior fossa or arising from the basilar artery (BA) and its branches continue to be viewed as technical challenges by most practicing neurosurgeons. There are four traditional approaches to these lesions. Both the transsylvian (pterional) and subtemporal approaches have been used with great success for those lesions located near the basilar apex.[2,8,30,31] For the more caudally situated lesions of the vertebral artery (VA), including those of posterior inferior cerebellar artery (PICA) origin, the retrosigmoid craniectomy is a commonly practiced and effective strategy. For uncommon lesions of the BA trunk or anterior inferior cerebellar artery (AICA), a combined supra- and infratentorial approach as originally proposed by Drake[8] has provided an innovative strategy and has also served as a harbinger for technical advances. These techniques have withstood the test of time and are used for the majority of posterior circulation aneurysms. However, with large or giant aneurysms that necessitate greater exposure or for those uncommon lesions of the BA trunk for which it is hazardous to extend a traditional approach, more innovative approaches based on evolving principles of cranial base surgery may provide certain benefits. The principles underlying most cranial base surgical strategies include the following: 1) shortest trajectory to the lesion; 2) bone removal in lieu of brain retraction; 3 ) maximization of extradural exposure; 4) skeletonization/decompression of cranial nerves and vascular structures; and 5) reconstitution of all dural openings. Using these tenets, we have expanded on existing approaches and in certain circumstances have developed alternative approaches to large and complex aneurysms of the posterior circulation. $[5,11]$

\section{CLINICAL MATERIAL AND METHODS}




\section{Patient Population}

All patients in this series were treated in Los Angeles at either the Los Angeles County/University of Southern California (USC) Medical Center, USC University Hospital, or Children's Hospital of Los Angeles. This group included 30 patients harboring various aneurysms of the posterior fossa. Patient data, surgical approach, and results are summarized in Table 1. Outcomes were categorized according to the Glasgow Outcome Scale.[18]

\section{TABLE 1}

CLNICAL CHARACTERISTKS OF 30 PATIENTS TREATED WITH CRANIAL BASE APPROACHES FOR POSTERIOR CIRCULATION ANEURYSMS*

\begin{tabular}{|c|c|c|c|c|c|c|}
\hline $\begin{array}{l}\text { Case } \\
\text { No. }\end{array}$ & $\begin{array}{l}\text { Age } \\
(y s) \\
\text { Sex }\end{array}$ & Presertation & Lesion & Approach & Complications & Outcome \\
\hline 1 & $39, F$ & $\begin{array}{l}\text { mass effect, } \\
\text { CN III } \\
\text { paresis }\end{array}$ & giant BA tip & $\begin{array}{l}\text { tem poropolar, } \\
\text { hypothermic } \\
\text { arrest }\end{array}$ & none & normal \\
\hline 2 & $68, F$ & incidentil & high BÁ tip & $\begin{array}{l}\text { tem poropolar, } \\
\text { transzygo- } \\
\text { matic }\end{array}$ & none & normal \\
\hline 3 & $54, M$ & Sn H & lange BÁ tip & tem poropolar & vasospasm & $\begin{array}{l}\text { moderate } \\
\text { deficit }\end{array}$ \\
\hline 4 & $32, F$ & mass effect & giant Вд́ tip & $\begin{array}{l}\text { temporopolar, } \\
\text { hypothermic } \\
\text { arrest }\end{array}$ & hemiparesis & $\begin{array}{l}\text { moderate } \\
\text { deficit }\end{array}$ \\
\hline $\begin{array}{l}5 \\
6\end{array}$ & $\begin{array}{l}59, F \\
46, F\end{array}$ & $\begin{array}{l}\text { incidental } \\
\operatorname{SAH}\end{array}$ & $\begin{array}{l}\text { high } B A ́ \text { tip } \\
\text { high BÁ tip }\end{array}$ & $\begin{array}{l}\text { tem poropolar } \\
\text { tem poropolar }\end{array}$ & $\begin{array}{l}\text { none } \\
\text { memoryloss }\end{array}$ & $\begin{array}{l}\text { normal } \\
\text { moderate } \\
\text { deficit }\end{array}$ \\
\hline 7 & $52, F$ & SAH & low BA tip & temporopolar & none & normal \\
\hline 8 & 38, M & $\begin{array}{l}\text { SAH } \\
\text { (Grade III) }\end{array}$ & high BÁ tip & tem poropolar & none & normal \\
\hline 9 & $49, F$ & $\begin{array}{l}\text { SÀ } \mathrm{H} \\
\text { (Grade III) }\end{array}$ & giant BÁ & $\begin{array}{l}\text { tem poropolar, } \\
\text { hypothermic } \\
\text { arrest }\end{array}$ & $\begin{array}{l}\text { in trao p rupture, } \\
\text { PCA ocdusion }\end{array}$ & $\begin{array}{l}\text { Severe } \\
\text { deficit }\end{array}$ \\
\hline 10 & $65, M$ & incidental & lo w BA tip & $\begin{array}{l}\text { tem poropolar, } \\
\text { transzygo- } \\
\text { matic }\end{array}$ & mound infection & normal \\
\hline 11 & $79, F$ & SÁH & large BÁ trunk & $\begin{array}{l}\text { com tined pe- } \\
\text { trosel, retro- } \\
\text { labyrinthine }\end{array}$ & none & normal \\
\hline 12 & $50, F$ & $\begin{array}{l}\text { SAH } \\
\text { (Grade III) }\end{array}$ & BÁ trunk & $\begin{array}{l}\text { com tined pe- } \\
\text { trosel, retro- } \\
\text { labyrinthine }\end{array}$ & none & $\begin{array}{l}\text { moderate } \\
\text { deficit }\end{array}$ \\
\hline $\begin{array}{l}13 \\
14\end{array}$ & $\begin{array}{l}42, \mathrm{~F} \\
39, \mathrm{M}\end{array}$ & $\begin{array}{l}\text { SnH } \\
\text { SnH }\end{array}$ & $\begin{array}{l}\text { VB junction } \\
\text { AICA }\end{array}$ & $\begin{array}{l}\text { RLTS } \\
\text { RLTS }\end{array}$ & $\begin{array}{l}\text { wocal cord paresis } \\
\text { CSF leak }\end{array}$ & $\begin{array}{l}\text { normal } \\
\text { normal }\end{array}$ \\
\hline 15 & $43, \mathrm{~F}$ & $\mathrm{SAH}$ & distal VÁ & RLTS & none & normal \\
\hline 16 & $27, F$ & S̆ H & WB junction & RLTS & none & normal \\
\hline 17 & $26, F$ & SAH & BÁ trunk & RLTS & hearing loss & normal \\
\hline 18 & $58, F$ & SnH & WB junction & RLTS & $\begin{array}{c}\text { in trao p rupture, wo- } \\
\text { cal cord paresis }\end{array}$ & norma \\
\hline 19 & $47, M$ & $\begin{array}{l}\text { abducens } \\
\text { palsy, SAH }\end{array}$ & distal VA & RLTS & mound infection & normal \\
\hline 20 & $48, M$ & $\mathrm{SAH}$ & distal VA & RLTS & none & normal \\
\hline 21 & 51 , M & SAH & VB junction & RLTS & none & normal \\
\hline 22 & $27, M$ & SAH & VB junction & RLTS & $\begin{array}{l}\text { in traop rupture, CN } \\
10 \& 12 \text { paresis }\end{array}$ & normal \\
\hline 23 & 68, M & $\mathrm{SAH}$ & giant BÁ trunk & RLTS & $\begin{array}{l}\text { hearing loss, unable } \\
\text { to dip, repeated } \\
\text { SAH } 1 \text { wk postop }\end{array}$ & dead \\
\hline 24 & $69, M$ & SAH & large BÁ trunk & ELITE & incomplete dip & moderate \\
\hline
\end{tabular}




\begin{tabular}{|c|c|c|c|c|c|c|}
\hline & & (Gaue III) & & & "gauorl & Delat \\
\hline 25 & $50, F$ & $\mathrm{SAH}$ & VÁ & ELITE & none & normal \\
\hline 26 & $47, \mathrm{~F}$ & SAH & VA & ELITE & none & normal \\
\hline 27 & $44, F$ & Sn H & VÁ & ELITE & none & normal \\
\hline 28 & $40, F$ & $\begin{array}{l}\text { SAH } \\
\text { (Grade III) }\end{array}$ & VA & ELITE & $\begin{array}{l}\text { in trao p rupture, } \\
\text { sactifice of Plch, } \\
\text { wocal cord paresis }\end{array}$ & normal \\
\hline $\begin{array}{l}29 \\
30\end{array}$ & $\begin{array}{l}12, M \\
63, \mathrm{M}\end{array}$ & $\begin{array}{l}\mathrm{SAH} \\
\text { mass effect }\end{array}$ & $\begin{array}{l}\text { fusiform VA } \\
\text { giant } V B \\
\text { junction }\end{array}$ & $\begin{array}{l}\text { ELITE } \\
\text { ELITE }\end{array}$ & $\begin{array}{l}\text { none } \\
\text { BA throm bosis }\end{array}$ & $\begin{array}{l}\text { normal } \\
\text { dead }\end{array}$ \\
\hline
\end{tabular}

${ }^{\circ} \mathrm{CN}=$ cranial nerve; CSF = ceretrospinal fluid; ELITE = extreme-lateral inferior transtubercular exposure; $\mathrm{PCA}=$ posterior cere tral artery, RLTS = retrolabyrinthine-transsigmoid; VB = vertetrobasilar.

\section{Extradural Temporopolar Approach}

A detailed description of this approach has been reported previously[5] and will only be briefly highlighted here. Figure 1 illustrates the key steps and the final exposure obtained via this approach. The patient is positioned as for a transsylvian procedure. After removal of the frontotemporal bone flap, the dura is stripped from both frontal and temporal fossae and all bone excrescences are flattened or removed by means of a high-speed drill. The anterior clinoid process is totally removed and the optic canal, superior orbital fissure, and foramen rotundum are skeletonized. This allows the proper plane to be entered between the dura propria covering the temporal lobe and the outer cavernous membrane. Sharp dissection is used to accomplish this maneuver. A self-retaining retractor blade is shifted as dissection proceeds, retracting the temporal pole posteriorly under dural protection. This step is key to dramatically widening the typical transsylvian exposure. 


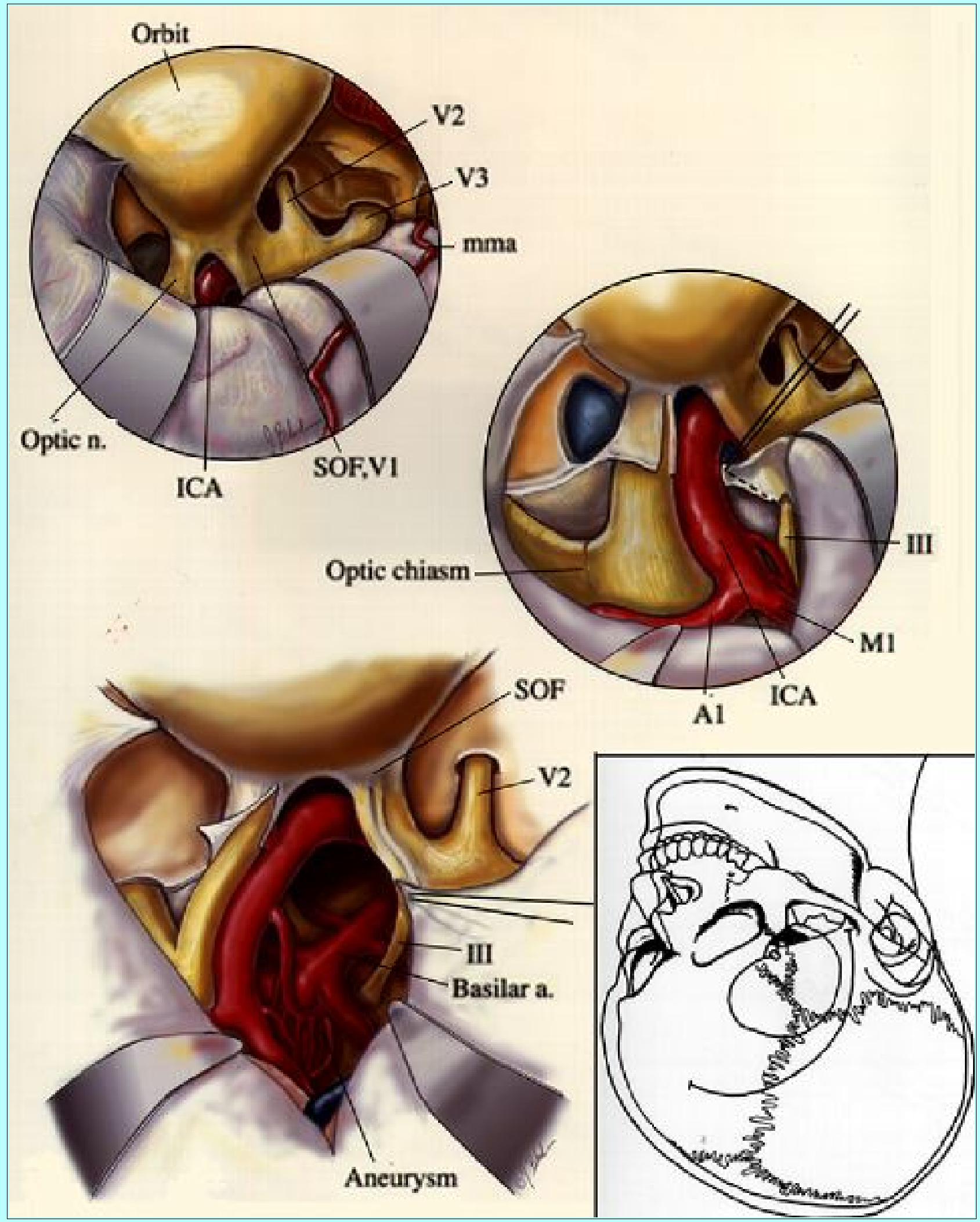

Fig. 1. Drawings illustrating the defining maneuvers of the temporopolar approach. Extensive extradural bone removal and extradural dissection of the cavernous sinus result in posterior displacement of the temporal lobe under protection of the dura (upper left). After dural incision, the fibrous carotid ring is dissected in addition to opening of the anterior petroclinoidal ligament (dotted line) and liberation of the proximal segment of the oculomotor nerve (upper right) to widen exposure of the basilar caput and the aneurysm (lower left). Inset: Line drawing illustrating the scalp incision and typical pterional type 
bone flap made for the approach. $\mathrm{a} .=$ artery; ICA $=$ internal carotid artery; $\mathrm{mma}=$ middle meningeal artery; $\mathrm{n} .=$ nerve; $\mathrm{SOF}=$ superior orbital fissure; V1, V2, and V3 = first, second, and third division of the trigeminal nerve; III = cranial nerve III.

The dura over the sylvian fissure is opened along with the optic nerve sheath. The fibrous carotid ring is then freed from the artery, allowing for later mobilization. The sylvian fissure is dissected and the frontal lobe gently retracted. The medial triangle of the cavernous sinus (bounded by the lateral wall of the intradural carotid, oculomotor nerve, and the posterior clinoid process) is opened after incising the anterior petroclinoidal ligament and opening the porous oculomotorius, allowing mobilization of the third cranial nerve. The resulting dural flap, which is contiguous with the incisural edge, may be either retracted with a suture or excised to expand the exposure. With the carotid artery retracted medially and the oculomotor nerve mobilized laterally, the posterior clinoid process can be removed to expand exposure inferiorly to obtain proximal control of the BA. Obligate cavernous sinus bleeding is controlled with judicious packing of oxidized cellulose. For high-riding BA lesions, removal of the zygoma further expands the exposure and allows the surgeon to angle the operating microscope to an exaggerated inferior-to-superior trajectory.[13,17]

\section{Combined Petrosal Approach}

Several authors have contributed to the development of this approach and have previously described it in detail.[1,12,14,29] In brief, a retromastoid skin incision is extended approximately $5 \mathrm{~cm}$ above the external auditory meatus and curved gently forward, ending anterior to the tragus. A partial mastoidectomy skeletonizing the labyrinth, posterior fossa dura, sigmoid sinus, and superior petrosal sinus is combined with an L-shaped craniotomy around the ear to complete the bone exposure. The key maneuver involves opening the presigmoid posterior fossa dura in conjunction with ligation of the superior petrosal sinus and incising the tentorium to the tentorial incisura, as is demonstrated in Fig. 2. This allows for simultaneous gentle retraction of the sigmoid sinus and cerebellum posteriorly. We prefer to open the dura in such a way as to minimize the amount of brain surface exposed. Our method allows retraction of the temporal lobe under the protective dura. This also protects the vein of Labbe from stretching or tearing, although not from compression. Potential complications from compression of the vein of Labbé are avoided by using only intermittent retraction when absolutely necessary. Opening the arachnoid and looking medially past cranial nerves five through 10 results in a panoramic view of the middle to upper BA trunk and its ipsilateral branches. Exposure can be enhanced by removal of the bony labyrinth. This affords even more of a laterally situated basal trajectory, which further eliminates the need for any brainstem retraction. Unfortunately this approach does sacrifice hearing and the ipsilateral balance apparatus. Because watertight dural repair is difficult, an autologous adipose graft is placed in the mastoid defect. 


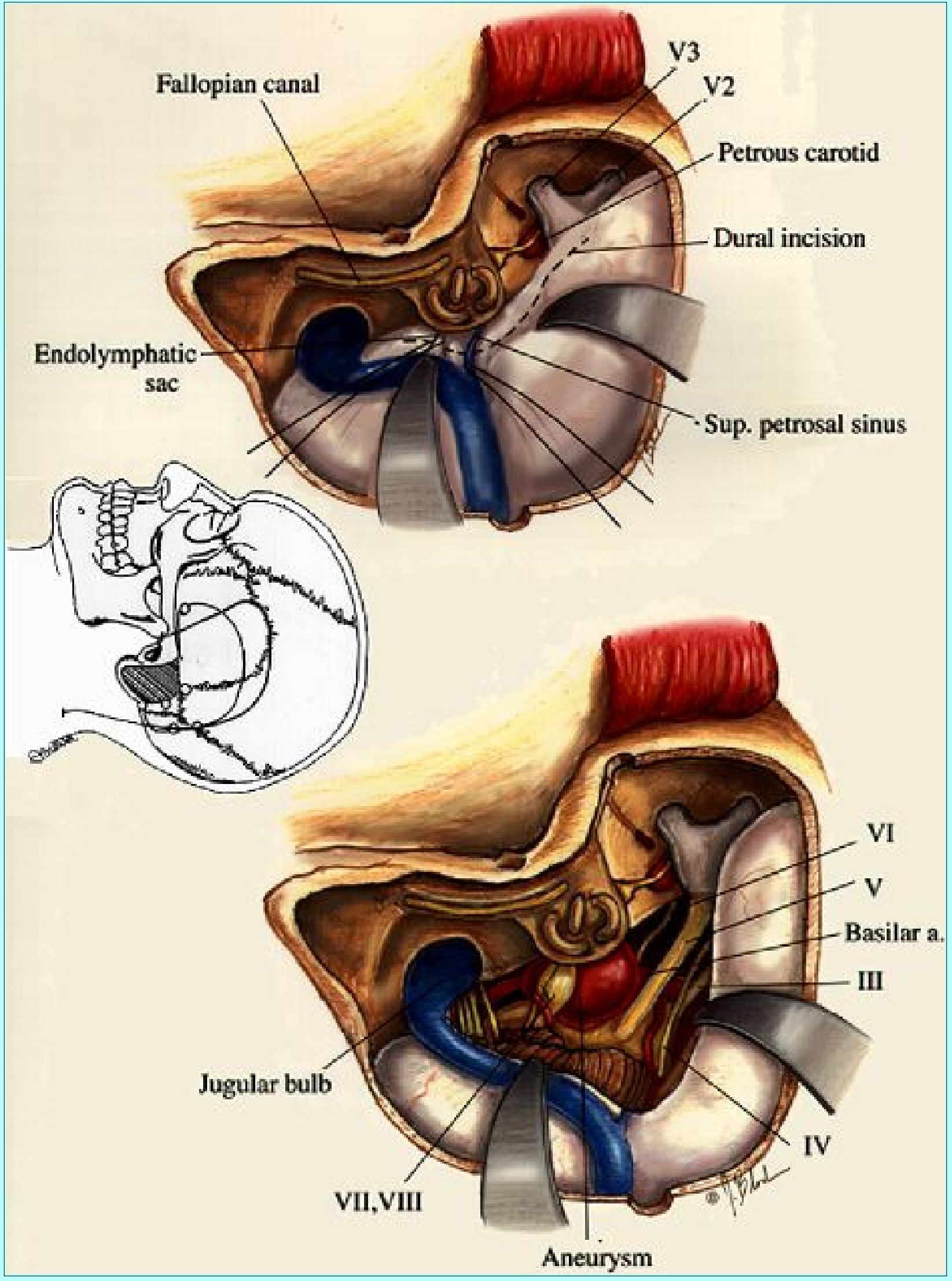

Fig. 2. Drawings illustrating procedures used in the combined petrosal approach. Upper: After the extradural bone resection is completed the dura is incised as shown by the dashed line. Lower: This incision is placed deep, such that the temporal lobe is mostly covered by dura under the retractor blades. The approach provides multiple viewing trajectories for optimum clip placement at the aneurysm neck. Inset: Drawing showing the scalp incision 
and bone opening for a left-sided approach. a. = artery; Sup. = superior; V2, V3 = second and third divisions of the trigeminal nerve; III, IV, V, VI, VII, and VIII = cranial nerves III through VIII.

The benefits of this approach include the opportunity for both proximal and distal control of the BA. The exposure is quite luxurious and allows for both a wide lateral approach and a cephalocaudad trajectory, as depicted in Fig. 2. Furthermore, the sigmoid sinus is preserved, which may be mandatory in those situations in which a dominant ipsilateral sigmoid sinus or incomplete communication of the transverse sinuses and the torcular herophili exists.

\section{Retrolabyrinthine-Transsigmoid Approach}

This approach was originally described in 1988 and applied to vascular lesions at the vertebrobasilar junction.[11] The patient is positioned supine with the head turned away from the side of approach. A retroauricular scalp incision is used and the soft tissues are reflected anteriorly to expose the back side of the external auditory meatus. An overview of the important steps of this approach is provided in Fig. 3. The technique involves a mastoidectomy with retrolabyrinthine exposure, skeletonizing the sigmoid sinus from its junction with the superior petrosal sinus to the jugular bulb. This allows the sigmoid sinus to be ligated at those two junctures and a dural flap to be reflected over the intact labyrinth, the key maneuver for this strategy. Fully skeletonizing the posterior semicircular canal widens the exposure. Accessible structures include the upper VA, vertebrobasilar junction, and lower BA trunk, up to and including the origin of the AICA. Because a watertight dural closure is somewhat problematic, closure is augmented with an autologous adipose graft placed in the mastoid defect. 


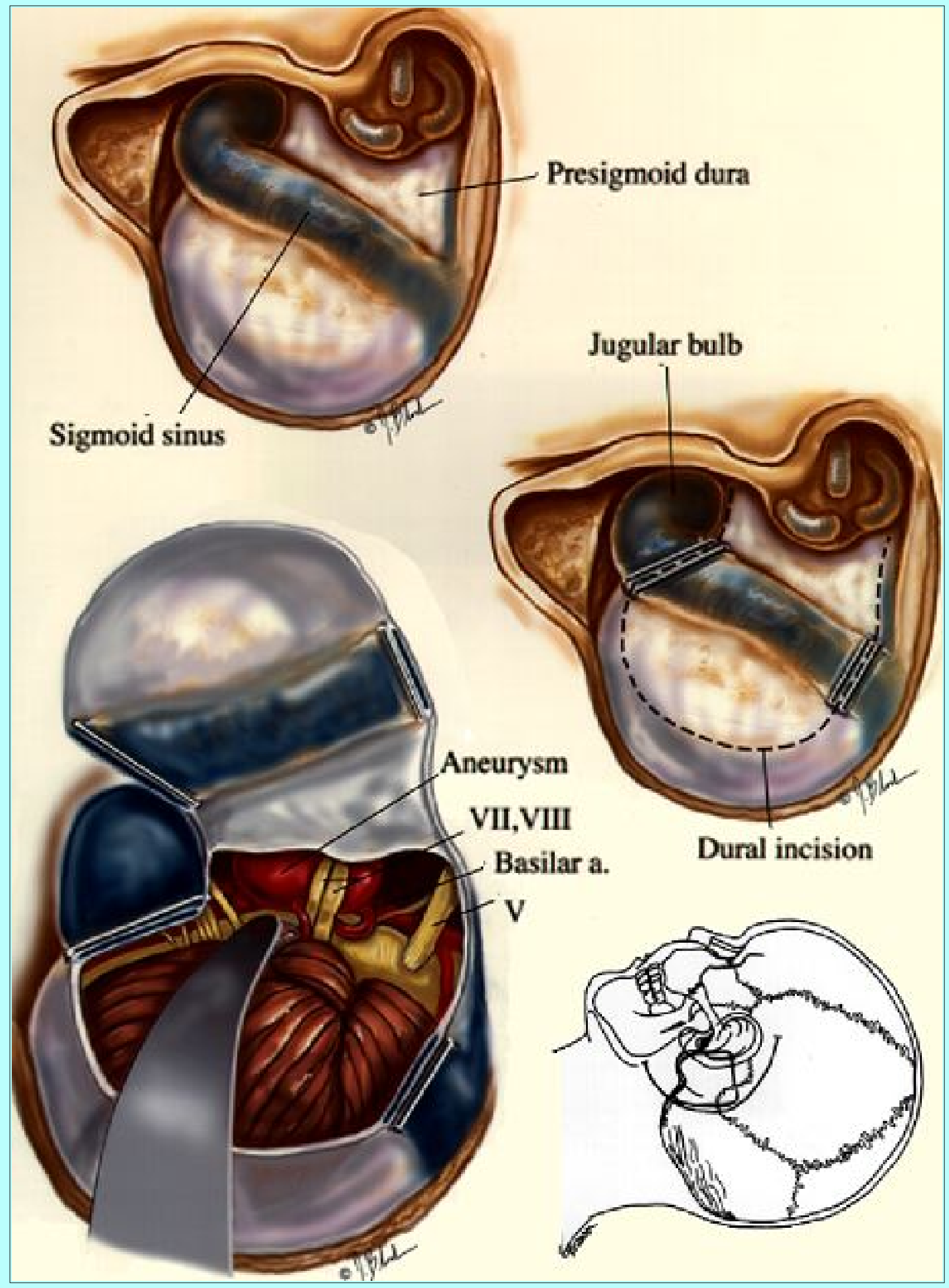

Fig. 3. Drawings depicting a complete mastoidectomy with skeletonization of the presigmoid and retrosigmoid dura that is initially performed for the RLTS approach (upper). The posterior semicircular canal is completely skeletonized. The sigmoid sinus is then ligated superior and inferior as part of dural opening (center). A wide retrolabyrinthine exposure of the vertebrobasilar junction area is afforded (lower). Inset: Drawing showing the retroauricular scalp incision and bone opening for a left-sided RLTS approach. a. = 
artery; V, VII, and VIII = cranial nerves.

\section{Extreme-Lateral Inferior Transtubercular Exposure}

Bertalanffy and Seeger[3] have provided a detailed description of this technique, which was developed in the 1970s by Dr. Seeger, as applied to vascular and neoplastic lesions. The important features of the approach include a lateral suboccipital craniectomy in conjunction with a limited mastoidectomy exposing the inferior sigmoid sinus and jugular bulb. The patient is placed in a lateral decubitus position. A lateral retromastoid incision is extended inferiorly to approximately the level of the C-3 transverse process. The muscle and soft tissues are reflected and the VA is isolated above the posterior arch of C-1. After a retromastoid craniectomy is extended through the foramen magnum, the inferior portion of the mastoid process is drilled away to expose the distal sigmoid sinus and jugular bulb (Fig. 4). The lateral portion of the $\mathrm{C}-1$ posterior arch is removed in selected cases requiring more inferior exposure. The remaining anterolateral rim of the foramen magnum is removed to include the posterior one-third of the occipital condyle. Drilling deeper in the anterior direction results in exposure of the hypoglossal canal. The jugular tubercle is reduced by removing bone between and medial to the hypoglossal canal and the jugular bulb. Removal of the anterolateral rim and jugular tubercle are the key steps in allowing anterior exposure of the lower brainstem. The dural opening parallels the entire length of the exposed sigmoid sinus and is continued inferiorly to the level of C-2. This allows the dura to be reflected laterally, carrying with it the inferior portion of the sigmoid sinus. The line of sight is parallel to the intracranial course of the VA without the need for brainstem retraction, as is demonstrated in Fig. 4. 


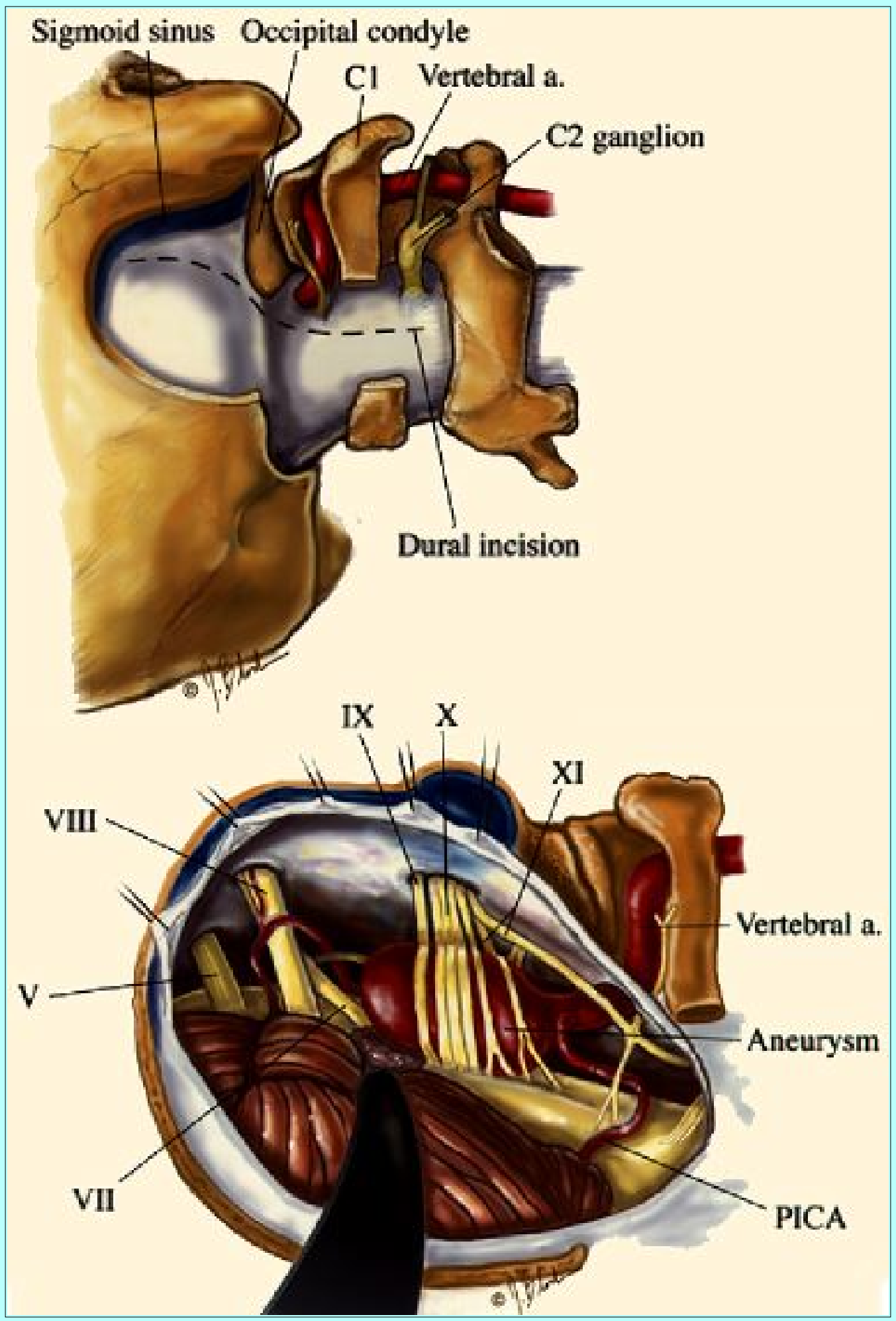

Fig. 4. Drawings showing the ELITE approach beginning with a lateral suboccipital craniectomy through the lateral foramen magnum and removal of the $\mathrm{C}-1$ lateral posterior hemiarch in selected cases (upper). The occipital condyle is subsequently further reduced and the hypoglossal canal is exposed. The jugular tubercle is then reduced by drilling between the hypoglossal canal and the jugular bulb. This approach provides wide exposure anterior to the brainstem with only a minimum of retraction to hold the cerebellar hemisphere away from the field (lower). a. = artery; V, VII, VIII, IX, X, and XI = cranial nerves. 


\section{Extradural Temporopolar Approach}

Ten patients were treated using the temporopolar approach. Three lesions were giant BA apex aneurysms, all of them partially thrombosed. Five aneurysms were located on elongated BAs, and two were associated with arteriovenous malformations fed by posterior cerebral arteries.

Two of the 10 patients presented with mass effect, with one of these being disabled preoperatively. Five presented with subarachnoid hemorrhage (SAH), two of whom were Grade III on the Hunt and Hess scale[16] preoperatively, and three patients presented with incidentally discovered aneurysms.

All lesions were successfully obliterated as documented by either intraoperative or postoperative angiography. There were two temporary and one permanent disabilities. The permanent disability was related to perforating vessel injury incurred during clip ligation of a large partially thrombosed lesion under hypothermic cardiac arrest. Two patients had temporary hemiparesis that reversed over a period of several weeks to several months. Three patients had varying degrees of third nerve paresis that completely resolved in each case.

\section{Combined Petrosal Approach}

We have treated two patients by means of this approach, both of whom had large upper BA trunk aneurysms and presented with SAH. Both lesions were successfully clip ligated. In one case, the approach was undertaken in the acute aftermath of an SAH. Because of our inability to gain exposure without retracting the brainstem, the labyrinth was sacrificed, causing permanent hearing loss. Otherwise there was no death or permanent disability in these two cases.

\section{Retrolabyrinthine-Transsigmoid Approach}

We have treated 11 patients using this approach. There was one giant lower BA trunk aneurysm and the other aneurysms were $15 \mathrm{~mm}$ or less in diameter. Of the 10 smaller lesions, five were located at the vertebrobasilar junction, two at the BA-AICA junction, and three were located in the distal VA. All patients presented with $\mathrm{SAH}$, although two of the cases were referred for treatment more than 6 months posthemorrhage. There was one death in the group. This patient presented with SAH from a giant BA trunk lesion that we were unable to clip ligate via this approach. While we were planning an alternative approach, the patient had a fatal repeated SAH. There were two patients who suffered hearing loss ipsilateral to the side of the approach but no patient had permanent deafness. All lesions except for the giant aneurysm were obliterated, as confirmed by either intra- or postoperative cerebral angiographic studies.

\section{Extreme-Lateral Inferior Transtubular Exposure}

Seven patients were treated by means of this approach. Two small distal VA aneurysms were approached in this manner because of the presence of a dominant sigmoid sinus. The remaining lesions were large or giant and occupied the vertebrobasilar junction. One patient presented with mass effect, and the other six presented with SAH.

There was one death in a patient with a giant unclippable lesion in which proximal VA ligation was ultimately performed. This patient did well for 8 hours, until thrombosis of the BA caused irreversible brainstem ischemia. Two patients, both of whom recovered satisfactorily, suffered temporary disability caused by lower cranial nerve injury. Intra- or postoperative angiographic studies demonstrated that all 
lesions were obliterated.

\section{DISCUSSION}

The four approaches described each provide for alternative strategies in the treatment of complex aneurysms of the posterior circulation. They allow the surgeon to take advantage of the tenets underlying contemporary cranial base surgery to protect cranial nerve function and reduce brainstem retraction. For the most part, these exposures are relatively luxurious, allowing large and giant lesions to be satisfactorily exposed and potentially obliterated. From the standpoint of both trajectory and breadth of exposure they fill the gaps between the three traditional approaches, namely the transsylvian, subtemporal, and suboccipital. True anterior approaches, such as the transoral and transfacial techniques, also obviate brain retraction. However, in our experience these techniques are typically limited in terms of the width of exposure and result in a deep operative field. Also, these strategies require operating through a field colonized by bacteria. Because of the added risk of infection, these techniques have been largely abandoned in our practice in cases of intradural lesions. We have yet to encounter an aneurysm for which a true anterior approach would be preferred over the "lateralized" trajectories presented here. Thus a comprehensive management paradigm exists for appropriate case selection based on the size and complexity of the lesion, the breadth of exposure, and the approach trajectory (Fig. 5).

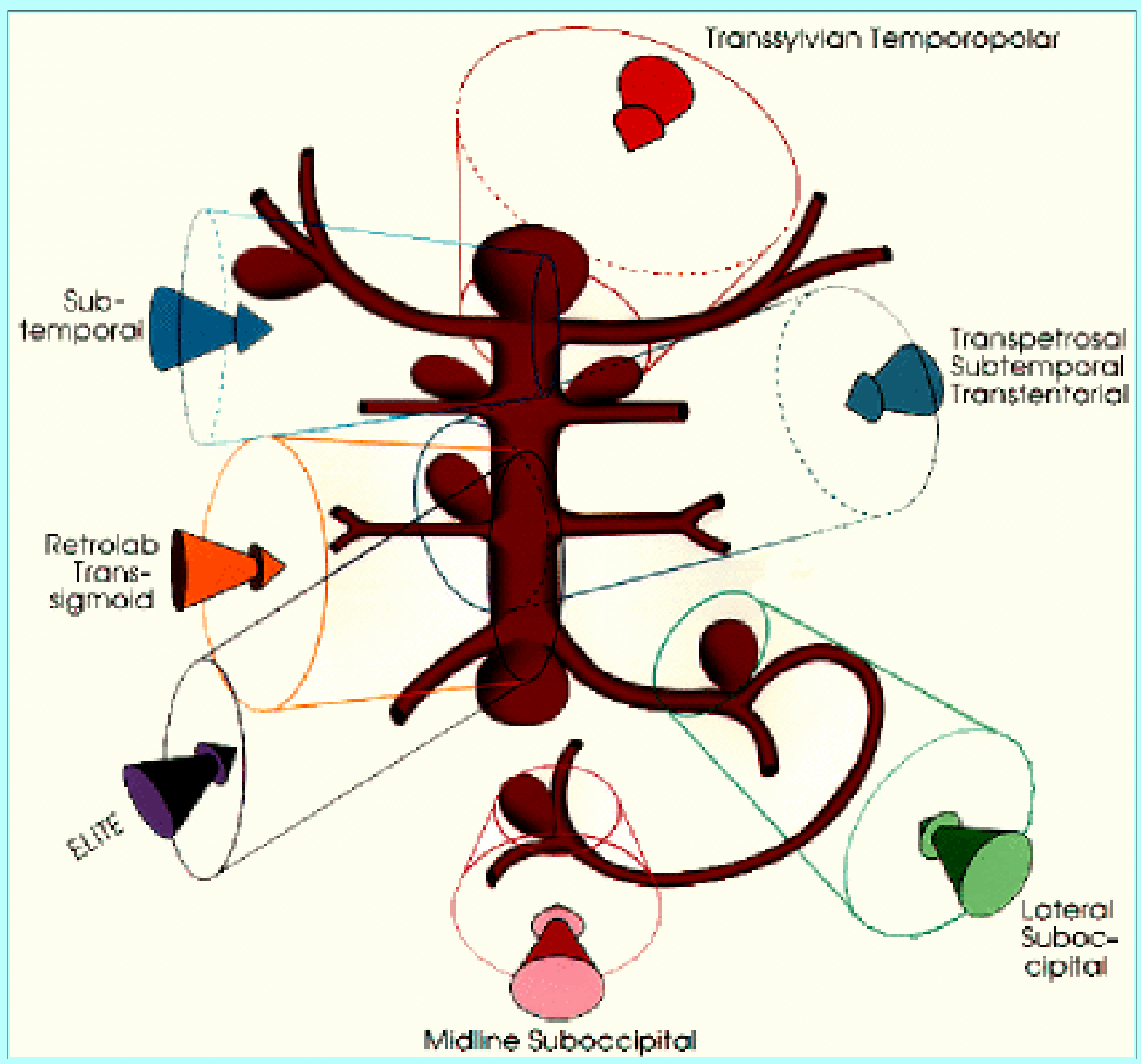

Fig. 5. Schematic diagram outlining the approach selection paradigm for posterior circulation aneurysms. Retrolab $=$ retrolabyrinthine. 


\section{Temporopolar Approach}

This technique has its roots in the standard pterional craniotomy popularized by Yasargil for treatment of anterior circulation aneurysms.[31] He and others quickly developed the method for use in BA tip lesions. In comparison to the traditional subtemporal approach first championed by Drake,[8] the pterional approach afforded a more anterior trajectory, facilitating exposure of the contralateral side of the lesion. To his credit, Drake also identified the occasional need for a more anterior trajectory, thereby developing the "half and half" approach for aneurysms of the BA bifurcation located above the dorsum sellae. Sano[25] and Dolenc, et al.,[7] contributed separately to the technique that most resembles the approach that we call temporopolar. Sano recognized that posterior mobilization of the temporal tip could result in a more anterior and lateral trajectory as compared with the traditional pterional approach. In addition to the optional removal of the zygoma, the operating microscope can be deflected in a more lateral-to-medial and inferior-to-superior direction, such that superiorly placed BA apex aneurysms can be approached with relative ease. Our modification of these two strategies emphasizes the extradural exposure in an attempt to preserve the temporal tip veins.[5] The key features of this strategy include the following: extradural removal of the sphenoid ridge and anterior clinoid process; skeletonization/decompression of the optic canal, superior orbital fissure, and foramen rotundum; extradural retraction of the temporal lobe; transcavernous mobilization of the carotid artery and oculomotor nerve; transcavernous removal of the posterior clinoid process; and optional removal of the zygoma and/or superolateral orbital rim.

Dolenc, et al.,[7] and Fujimoto, et al.,[9] recognized that a transcavernous strategy adds several benefits. Transcavernous mobilization of the optic nerve, oculomotor nerve, and the carotid artery renders them more readily and safely retracted. For giant lesions around the BA apex, third cranial nerve retraction is often desirable. By radically freeing the oculomotor nerve from the lateral wall of the cavernous sinus, an extra length of the nerve can be gained to further improve its retractability. Transcavernous removal of the posterior clinoid process expands the working space for management of large and giant lesions, as well as providing for temporary occlusion of the middle portion of the BA.

The extradural temporopolar approach provides a wide anterolateral corridor to the parasellar compartment and upper BA.[5] Based on its breadth of exposure and trajectory, the temporopolar strategy combines the benefits of the transsylvian and subtemporal approaches. As such, it can serve as an alternative when BA apex or superior cerebellar artery (SCA) aneurysms are excessively large, in a high position, or pointing posteriorly. Typical indications would include giant aneurysms of the BA apex, high-riding and/or posterior-pointing apex lesions, and upper BA trunk lesions adjacent to the posterior clinoid process (Fig. 6). 


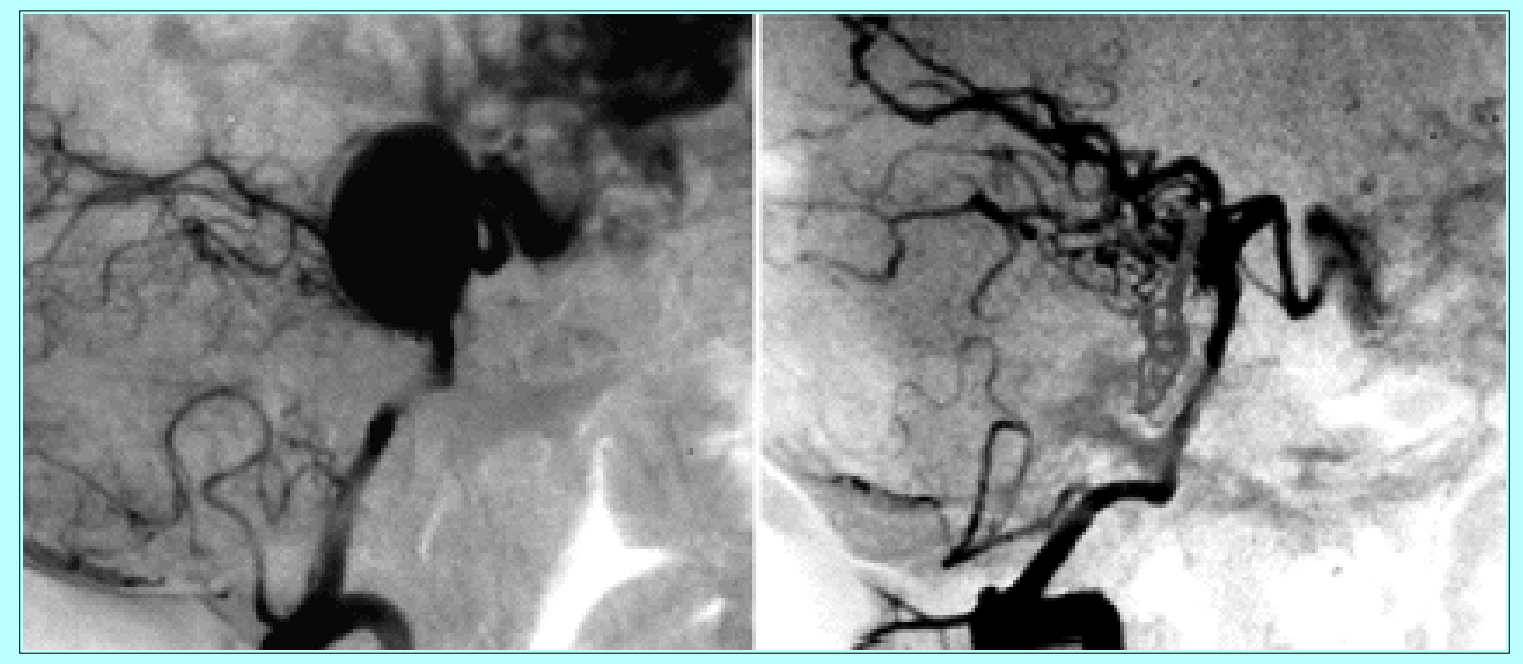

Fig. 6. Left: Lateral VA angiogram showing giant BA aneurysm in association with an anterior circulation arteriovenous malformation. The lesion presented as an oculomotor nerve palsy. Right: Postoperative angiogram demonstrating obliteration of aneurysm.

\section{Combined Petrosal Approach}

The combined petrosal strategy uses a supratentorial-to-infratentorial trajectory that expands the original subtemporal-transtentorial approach described by Peerless and Drake.[23] A number of authors have contributed to the development of this approach.[6,8,21,22] Both Drake[8] and Malis and colleagues[6,21] identified and reported the reasons for a combined supra-infratentorial approach to aneurysms in this region. Hashi and colleagues[14] eloquently described such a strategy in the late 1970s. Samii, et al.,[24] further refined the technique for use in managing petroclival tumors. Most recently, Seifert and Stolke[26] detailed their experience with such an approach in nine patients with large and complex vertebrobasilar aneurysms. Variations of this approach have been described previously, especially for use in cranial base neoplasms.[1,12,14,19-22,29] Accessible structures include the BA trunk, the SCA, AICA, and in many circumstances the vertebrobasilar junction.

The indications for this approach include BA trunk aneurysms originating near the origin of the AICA up to and including the origin of the SCAs. For middle or upper BA trunk aneurysms, this strategy provides the most versatile option for proximal and distal control. The approach is particularly useful for large or giant lesions in this vicinity (Fig. 7). 


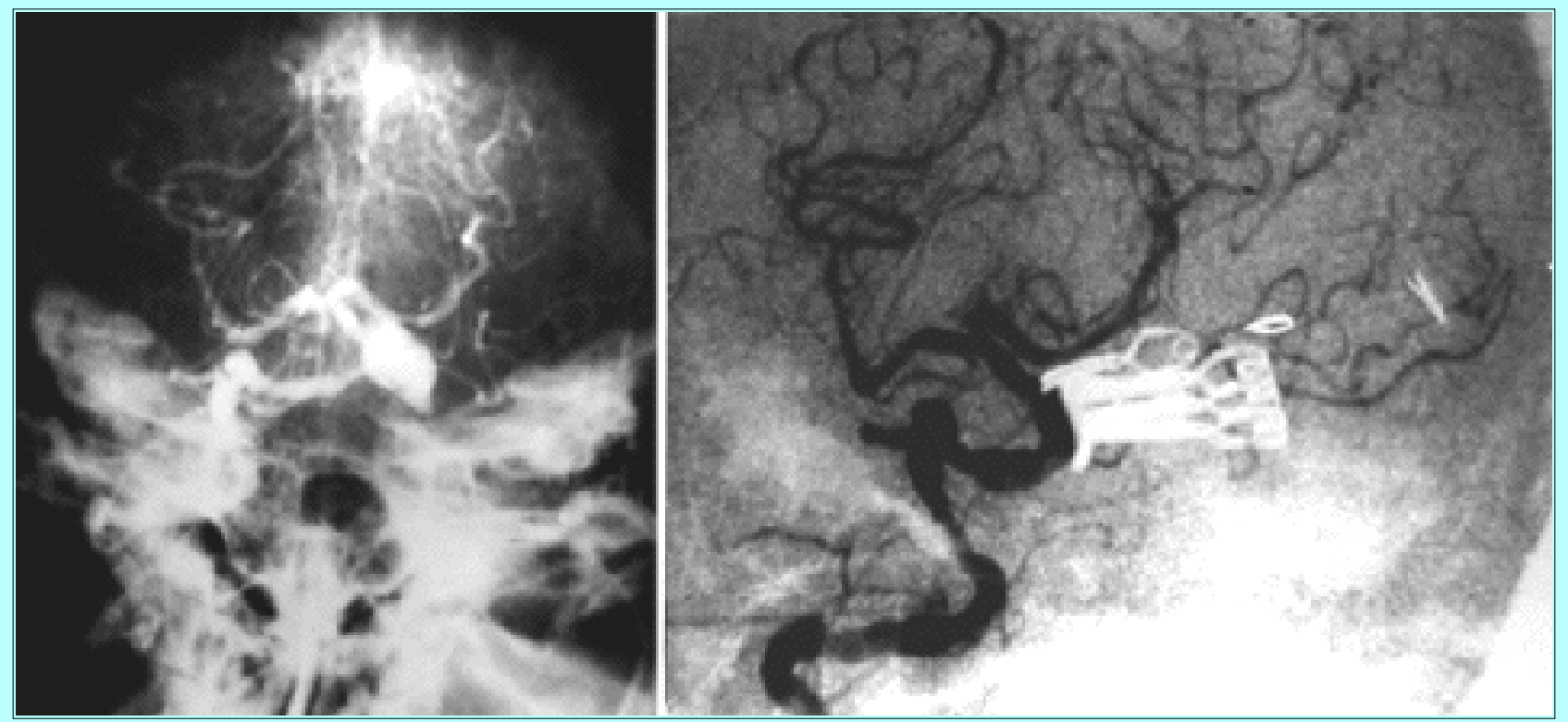

Fig. 7. Left: Anteroposterior angiogram of a large upper BA trunk aneurysm presenting in an elderly woman with SAH and multiple associated aneurysms. Right: Postoperative angiogram obtained after successful clip ligation via a combined petrosal approach.

The benefits of such an approach involve the limitation of brain retraction because of a more lateral-to-medial and superior-to-inferior trajectory. Furthermore, the sigmoid sinus is preserved. Using a retrolabyrinthine technique, hearing may also be preserved. Radical removal of the petrous apex is usually unnecessary for treatment of vascular lesions, making the approach not only relatively quick to accomplish but relatively easy to learn. The superoinferior, lateral-to-medial trajectory and wide exposure position this approach nicely between the transsylvian-subtemporal strategies and the suboccipital approach.

\section{Retrolabyrinthine-Transsigmoid Approach}

The RLTS approach was originally described in 1988[11] as a method to open a lateral corridor to the lower BA trunk, vertebrobasilar junction, and distal portion of the VA. It is based on the traditional retrolabyrinthine-transmastoid strategy used by otologists to gain limited access to the cochlear and vestibular nerves in the cerebellopontine angle.[4,28] Although the retrolabyrinthine technique affords a basolateral trajectory to the vertebrobasilar junction, the exposure had to be expanded to deal with larger lesions such as aneurysms. Hence, in selected individuals, ligation of the sigmoid sinus can be added.

Indications for this approach include small and large lesions near the vertebrobasilar junction and AICA origin (Fig. 8). Preoperative angiography must demonstrate the potential for adequate collateral venous outflow and the lack of an overwhelmingly dominant sigmoid sinus and internal jugular vein ipsilateral to the side of the approach. This approach is ipsilateral to the side of the BA on which the neck of the aneurysm arises in strongly lateralized lesions. In midline lesions, namely those that project either dorsally or ventrally, the side of approach is governed by the side of the smallest sigmoid sinus. 


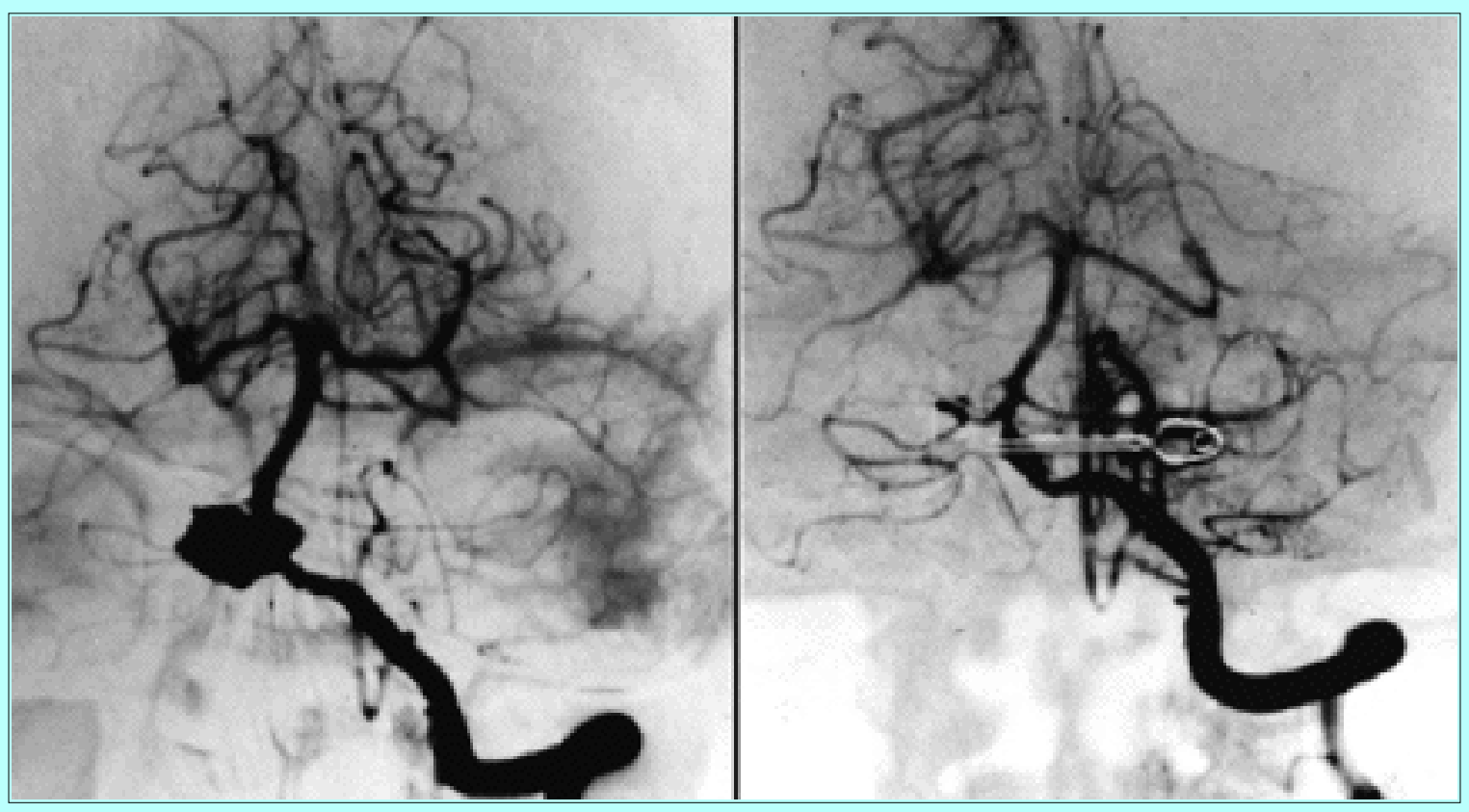

Fig. 8. Left: Preoperative anteroposterior angiogram showing a vertebrobasilar junction aneurysm. Right: Postoperative angiogram showing that the lesion, via the RLTS approach, was successfully clip ligated.

From the time that we developed this approach, experience at our institution has continued to validate the effectiveness and simplicity of a virtually straight lateral-to-medial trajectory to the vertebrobasilar junction.[11] Aneurysms of the AICA-BA junction, lower BA trunk, and vertebrobasilar junction can be approached without the need for brain retraction. Further experience has indicated that the approach should be limited to lesions less than $2 \mathrm{~cm}$ in diameter so that proximal and distal control can be more easily effected. As with any approach to this region, morbidity relates not only to brain retraction but also to injury to the lower cranial nerves. Indeed, we have had two cases in which prolonged tracheostomy necessitated by vocal cord paralysis complicated recovery.

We recommend that aneurysms be approached from the side to which they point. This allows for the most versatility in terms of clip placement, as well as avoidance of injury to surrounding perforating vessels. For lesions that point dorsally or ventrally, the side of approach is predicated on the relative size of the sigmoid sinuses. In two instances in which the sigmoid sinus was larger on the side of the approach, temporary occlusion with observation of the brain combined with manometric measurement of intrasinus pressure allowed judicious ligation. Less than a 5- $\mathrm{mm} \mathrm{H}_{2} \mathrm{O}$ rise in sinus pressure is probably safe for ultimate ligature.

The RLTS approach serves as a simple alternative to the more involved strategies for lesions in the region of the lower BA trunk, such as the combined petrosal or the far-lateral (ELITE) approaches. When lesions are giant or the sigmoid sinus cannot be sacrificed, the RLTS approach is not recommended.

\section{Extreme-Lateral Inferior Transtubercular Approach}

This approach is a natural extension of the far-lateral suboccipital approach as originally proposed by Heros.[15] As such, it affords an inferior-to-superior trajectory combined with a lateral-to-medial trajectory to the lower clivus and vertebrobasilar complex.[3,10,27] The view afforded anterior to the brainstem obviates the need for lower brainstem retraction. This strategy serves as a useful alternative to the RLTS approach when aneurysms are giant or are strongly lateralized to the side of a dramatically 
dominant sigmoid sinus. Indications include giant VA, PICA, distal VA, giant vertebrobasilar junction, and giant lower BA trunk lesions (Fig. 9).

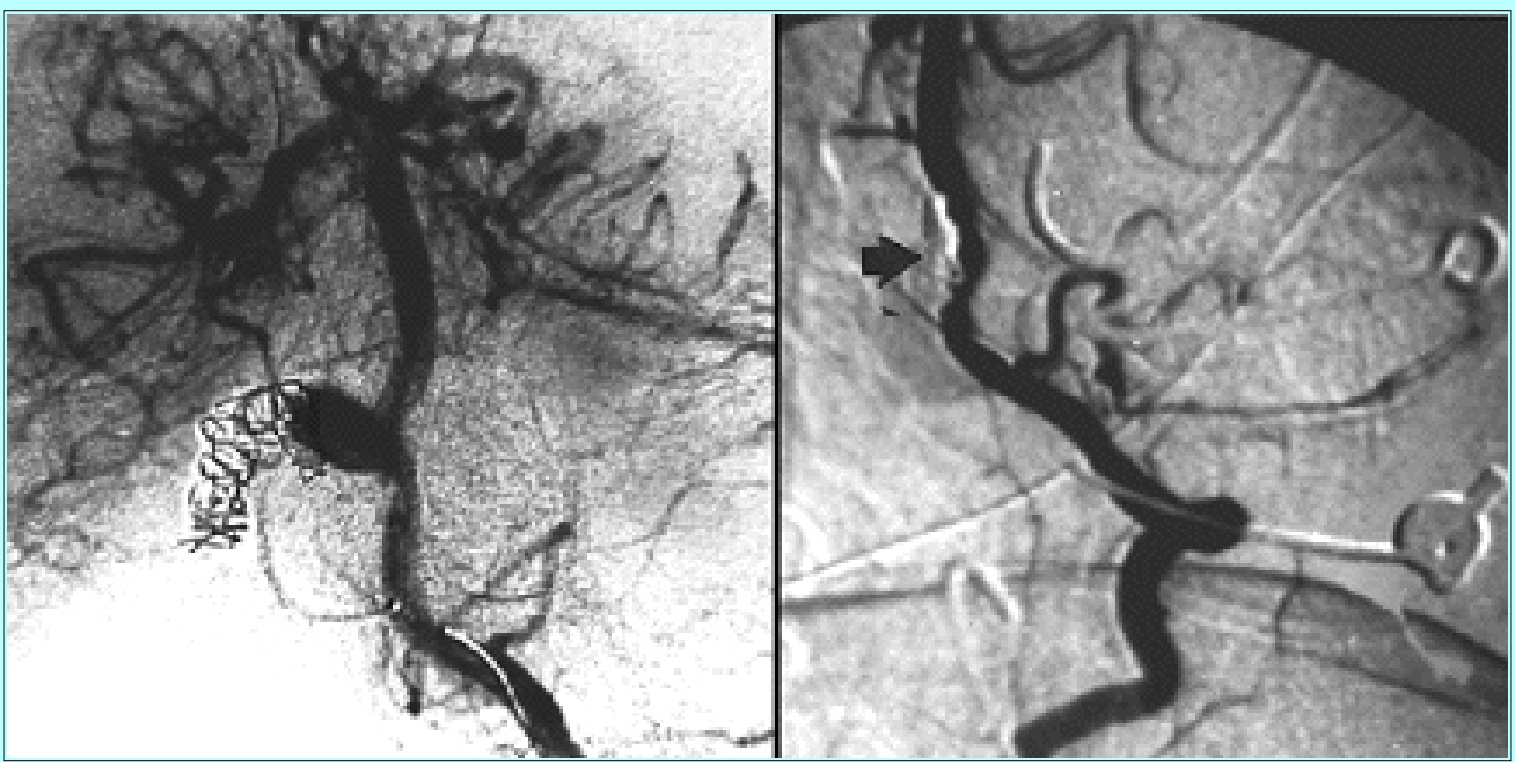

Fig. 9. Left: Angiogram showing a partially occluded distal VA aneurysm in a 12-year-old boy. The ipsilateral VA has been sacrificed in the coiling process. Right: Intraoperative angiogram showing clip ligation (arrow). Because of the relative sizes of the sigmoid sinuses, the ELITE approach was chosen.

The trajectory of this technique is anterolateral to the medulla and upper cervical spinal cord, sacrificing bone in lieu of lower brainstem and upper cervical spinal cord retraction. Such an expanded approach affords the surgeon a view superior to the vertebrobasilar junction and lower BA trunk. The extradural exposure of the VA above the $\mathrm{C}-1$ posterior arch allows for proximal vascular control. One unavoidable drawback is the necessity to work through the network of lower cranial nerves. The major morbidity associated with this approach involves vocal cord paralysis and the possibility of aspiration pneumonia.

We have specifically used this approach for giant lesions of the VA and vertebrobasilar junction. Although it is more time-consuming and tedious than the RLTS approach, for giant lesions the exposure is more open, which increases the versatility of the approach. The most common use of the approach in our hands has been for cranial base tumors. Those cases, in conjunction with our vascular cases, have led us to believe that there is no significant risk of craniocervical junction instability. However, biomechanical studies in cadavers are now being conducted to confirm our clinical impressions.

\section{CONCLUSIONS}

Admittedly, use of these cranial base techniques will be required for relatively few posterior circulation lesions. The traditional transsylvian, subtemporal, and retrosigmoid approaches are versatile enough to treat the majority of vertebrobasilar aneurysms. However, those surgeons who wish to develop the requisite skills in the cranial base laboratory can take advantage of a paradigm such as the one proposed to treat virtually all posterior circulation lesions. Conceptually, a 360š strategy can result.

\section{References}

1. Al-Mefty O, Fox JL, Smith RR: Petrosal approach for petroclival meningiomas. Neurosurgery 22:510-517, 1988 
2. Batjer HH, Samson DS: Causes of morbidity and mortality from surgery of aneurysms of the distal basilar artery. Neurosurgery 25:904-916, 1989

3. Bertalanffy H, Seeger W: The dorsolateral, suboccipital, transcondylar approach to the lower clivus and anterior portion of the craniocervical junction. Neurosurgery 29:815-821, 1991

4. Brackmann DE, Hitselberger WE: Retrolabyrinthine approach: technique and newer indications. Laryngoscope 88:286-297, 1978

5. Day JD, Giannotta, SL, Fukushima T: Extradural temporopolar approach to lesions of the upper basilar artery and infrachiasmatic region. J Neurosurg 81:230-235, 1994

6. Decker RE, Malis LI: Surgical approaches to midline lesions at the base of the skull: a review. Mt Sinai J Med 37:84-102, 1970

7. Dolenc VV, Skrap M, Sustersic J, et al: A transcavernous-transsellar approach to the basilar tip aneurysms. Br J Neurosurg 1:251-259, 1987

8. Drake CG: The treatment of aneurysms of the posterior circulation. Clin Neurosurg 26:96-144, 1979

9. Fujimoto Y, Ikeda H, Yamamoto S: [Pterional transcavernous approach for large basilar top aneurysm--significance of the exposure of Dolenc's triangle.] Surg Cereb Stroke 20:191-195, 1992 (Jpn)

10. George B, Dematons C, Cophigon J: Lateral approach to the anterior portion of the foramen magnum. Application to surgical removal of 14 benign tumors: technical note. Surg Neurol 29:484-490, 1988

11. Giannotta SL, Maceri DR: Retrolabyrinthine transsigmoid approach to basilar trunk and vertebrobasilar artery junction aneurysms. Technical note. J Neurosurg 69:461-466, 1988

12. Hakuba A, Nishimura S, Inoue Y: Transpetrosal-transtentorial approach and its application in the therapy of retrochiasmatic craniopharyngiomas. Surg Neurol 24:405-415, 1985

13. Hakuba A, Tanaka K, Suzuki T, et al: A combined orbitozygomatic infratemporal epidural and subdural approach for lesions involving the entire cavernous sinus. J Neurosurg 71:699-704, 1989

14. Hashi K, Nin K, Shimotake K: Transpetrosal combined supratentorial and infratentorial approach for midline vertebro-basilar aneurysms, in Brock M (ed): Modern Neurosurgery I. Berlin: Springer-Verlag, 1982, pp 442-448

15. Heros RC: Lateral suboccipital approach for vertebral and vertebrobasilar artery lesions. J Neurosurg 64:559-562, 1986

16. Hunt WE, Hess RM: Surgical risk as related to time of intervention in the repair of intracranial aneurysms. J Neurosurg 28:14-20, 1968

17. Ikeda K, Yamashita J, Hashimoto M, et al: Orbitozygomatic temporopolar approach for a high basilar tip aneurysm associated with a short intracranial internal carotid artery: a new surgical approach.

Neurosurgery 28:105-110, 1991

18. Jennett B, Bond M: Assessment of outcome after severe brain damage. A practical scale. Lancet 
$1: 480-484,1975$

19. Kasdon DL, Stein BM: Combined supratentorial and infratentorial exposure for low-lying basilar aneurysms. Neurosurgery 4:422-426, 1979

20. Kawase T, Shiobara R, Toya S: Anterior transpetrosal-transtentorial approach for sphenopetroclival meningiomas: surgical method and results in 10 patients. Neurosurgery 28:869-876, 1991

21. Malis LI: Surgical resection of tumors of the skull base, in Wilkins RH, Rengachary SS (eds): Neurosurgery. New York: McGraw-Hill, 1985, Vol 1, pp 1011-1021

22. Miller CG, van Loveren HR, Keller JT, et al: Transpetrosal approach: surgical anatomy and technique. Neurosurgery 33:461-469, 1993

23. Peerless SJ, Drake CG: Posterior circulation aneurysms, in Wilkins RH, Rengachary SS (eds): Neurosurgery. New York: McGraw-Hill, 1985, Vol 2, pp 1422-1436

24. Samii M, Ammirati M, Mahran A, et al: Surgery of petroclival meningiomas: report of 24 cases. Neurosurgery 24:12-17, 1989

25. Sano K: Temporo-polar approach to aneurysms of the basilar artery at and around the distal bifurcation: technical note. Neurol Res 2:361-367, 1980

26. Seifert V, Stolke D: Posterior transpetrosal approach to aneurysms of the basilar trunk and vertebrobasilar junction. J Neurosurg 85:373-379, 1996

27. Sen CN, Sekhar LN: An extreme lateral approach to intradural lesions of the cervical spine and foramen magnum. Neurosurgery 27:197-204, 1990

28. Silverstein H, Norrell H: Retrolabyrinthine surgery: a direct approach to the cerebellopontine angle. Otolaryngol Head Neck Surg 88:462-469, 1980

29. Spetzler RF, Daspit CP, Pappas CTE: The combined supra- and infratentorial approach for lesions of the petrous and clival regions: experience with 46 cases. J Neurosurg 76:588-599, 1992

30. Yasargil MG, Antic J, Laciga R, et al: Microsurgical pterional approach to aneurysms of the basilar bifurcation. Surg Neurol 6:83-91, 1976

31. Yasargil MG, Fox JL: The microsurgical approach to intracranial aneurysms. Surg Neurol 3:7-14, 1975

Manuscript received June 18, 1996.

Accepted in final form May 22, 1997.

Address reprint requests to: Steven L. Giannotta, M.D., Los Angeles County/USC Medical Center, General Hospital, Suite 5046, 1200 N. State Street, Los Angeles, California 90033. 